\title{
Brain damage and the overlearning reversal effect
}

\author{
STEVEN GABRIEL, BART FREER, and STANLEY FINGER \\ Washington University, St. Louis, Missouri 63130
}

\begin{abstract}
Rats were either trained to criterion or given $100 \%$ overtraining on a tactile discrimination before receiving sham operations or frontal, somatic, or occipital cortex lesions. With preoperative training to criterion, the rats with frontal and somatic cortex lesions showed marked postoperative impairments when tested for reversal learning with the same tactile stimuli previously encountered, whereas animals with occipital cortex ablations did not differ significantly from sham-operated subjects. Preoperative overtraining failed to improve postoperative reversal learning among the sham-operated animals, and it did not attenuate the ablation effects displayed by rats with frontal or somatic cortex lesions. These data show that the overlearning reversal effect (ORE), which has been reported with visual and spatial stimuli, may be more difficult to demonstrate with tactile discriminanda. The findings further suggest that early reports of preoperative overtraining lessening postoperative lesion effects may have less generality than previously recognized.
\end{abstract}

The effects of preoperative "overtraining" (presenting additional learning trials after a reasonable criterion for mastery has been achieved) on relearning following brain damage has been the subject of relatively few investigations. This is surprising in that under some conditions postcriterion trials do seem to afford some "protection" against the consequences of subsequent brain damage, a finding with important theoretical and practical implications. Chow and Survis (1958) and Orbach and Fantz (1958), for example, have reported that preoperative overtraining aided visual discrimination retention following temporal neocortical ablations in monkeys, while Lukaszewska and Thompson (1967) noted that additional preoperative training also facilitated postoperative relearning of a visual pattern discrimination in rats with pretectal lesions. Although failures to find preoperative overtraining effects have also been reported (e.g., Bignami, Carro-Campi, \& Albert, 1968; Glendenning, 1972; Lashley, 1921), other results suggest that sparing effects like those described above may not be limited to just a few lesions and tasks. For instance, Thatcher and Kimble (1966) have shown that preoperative overtraining can improve active avoidance scores of rats with bilateral lesions of the amygdala (see also Fonberg, Brutkowski, \&

This research was supported by National Institute of Neurological Communicative Disease and Stroke Grant NS-11002 to the third author. The authors would like to thank Perry Sailor, Kathryn Taylor, and Anne Barry for their assistance on this project. A preliminary report of these data was presented at the Midwestern Psychological Association annual meeting in Chicago, May 1979. Requests for reprints should be sent to Stanley Finger, Department of Psychology, Washington University, St. Louis, Missouri 63130.
Mempel, 1962). More recently, it was noted that rats with extensive damage to the somatosensory cortices can relearn a tactile discrimination as rapidly as sham-operated animals when $100 \%$ overtraining is permitted prior to surgery (Weese, Neimand, \& Finger, 1973).

Overtraining was first demonstrated to facilitate reversal learning when Reid (1953) trained rats on a brightness discrimination in a Y-maze. This phenomenon, called the "overlearning reversal effect"' (ORE), has been the object of many laboratory studies (cf. Mackintosh, 1974; Paul, 1965; Sperling, 1965; Sutherland \& Mackintosh, 1971), and a number of theories have been proposed to account for it Denny, 1970; Hall, 1974; Lovejoy, 1966). Nevertheless, with very few exceptions (e.g., Gabriel, Saltwick, \& Kampschaefer, 1977), only visual and spatial stimuli have been used to assess the ORE in animals. Thus, the extent to which this phenomenon can generalize across tasks is not clear. In addition, because animals subjected to brain damage have not been tested in an ORE paradigm in the past, it is not known whether the beneficial effects of overtraining that are often witnessed with retention designs would also be observed under reversal conditions.

The present study represents an attempt to learn more about overtraining, injury to the cerebral cortex, and reversal learning, by subjecting trained and overtrained rats to various cortical lesions and testing them on tactile discriminanda for the ability to learn the reversal of a preoperatively encountered problem. It was expected that frontal, occipital, and somatic cortex lesions would impair reversal learning, in the latter case because tactile stimuli were 
to be used (Finger, 1974), and in the two former cases because previous experiments with other tasks have shown that reversal learning can be significantly impaired by these lesions (Bourke, 1954; Kolb, Nonneman, \& Singh, 1974; LeVere \& Morlock, 1973; Thorne \& Thompson, 1970). [It should be noted, however, that previous studies from this laboratory have shown that frontal and occipital cortex lesions have little apparent affect on nonreversal performance with tactile stimuli (e.g., Finger, Cohen, \& Alongi, 1972; Finger \& Frommer, 1968).] On the basis of the results of the retention studies reviewed above, it was further hypothesized that overtraining prior to surgery would attenuate the expected lesion effects on the reversal problem, and that it would improve the tactile reversal learning scores of animals in the sham-operated group.

\section{METHODS}

\section{Subjects}

Sixty-one naive male albino rats (CD strain; Charles River) served as subjects in the experiment. The animals were about 80 days of age and weighed approximately $200 \mathrm{~g}$ at the start of the investigation. They were housed by threes and fours in $30.5 \times$ $35.6 \times 17.8 \mathrm{~cm}$ plastic cages under constant illumination. Water was available ad lib, although food (Purina Rat Chow mixed with water) was restricted to a $15-\mathrm{min}$ period at the end of each test session.

\section{Apparatus}

The animals were tested for the ability to discriminate between two tactile surfaces in a T-maze constructed from plywood (see Finger \& Frommer, 1968). The startbox of the maze measured $30.4 \mathrm{~cm}$ in length, and a sheet metal guillotine door in the shape of an inverted $\mathrm{T}$ separated the startbox from the wings and the wings from each other.

Aluminum discriminanda taken from the set described by Finger and Frommer (1968) served as floors for the wings of the maze, each of which measured $95.0 \mathrm{~cm}$ in length and $8.9 \mathrm{~cm}$ in width. A plate with $1.57-\mathrm{mm}$-wide and $.79-\mathrm{mm}$-deep cuts was paired against a smooth, unmilled aluminum plate of equal height $(6.35 \mathrm{~mm})$. The grooves on the milled plate ran lengthwise from the choice point to the goal area at the end of the alley.

\section{Preoperative Training}

The animals were enucleated under ether anesthesia, and 2 weeks later were randomly assigned to (a) preoperative training or (b) preoperative overtraining conditions. Data were collected on 36 and 35 animals, respectively.

The milled plate was designated as the positive stimulus for half of the animals in each treatment group, while the smooth plate served as the positive stimulus for the remaining rats. Each subject received five test trials per day. The position of the positive stimulus in either the right or the left wing of the maze was determined by a random procedure, with the restriction that it not appear in the same wing more than three consecutive times for any animal on a given day. Rats within each group were run in a random order on each trial.

Olfactory cues were balanced by placing the food reward (Purina Rat Chow mixed with water) at the end of each discriminandum. However, a sheet metal barrier blocked the food cup in the wing containing the incorrect stimulus. A noncorrective method of testing was used; that is, the guillotine door was lowered as soon as a rat put all four paws on one of the aluminum surfaces. Animals were left in the maze for $20 \mathrm{sec}$, regardless of whether the choice was correct or incorrect. The maze was scrubbed with a lysol solution after each trial to minimize possible odor trails.

A criterion of perfect scores on 2 consecutive days was selected a priori to define learning. Subjects in the traditional learning group were removed from the preoperative task after meeting this criterion. In contrast, each animal in the overtraining group continued testing and received additional trials equal to the number required to reach criterion before being removed (100\% overtraining). Hence, a rat in the overtraining group that required 23 days to reach criterion was trained for a total of 46 days (230 trials) before testing terminated, while a rat that learned in 20 days (100 trials) experienced 200 test trials before being operated upon. Surgery was conducted 3-5 days after each animal completed preoperative training.

\section{Surgery}

The animals in each training condition were assigned to one of four surgical subgroups as they completed testing: (1) lesions of frontal cortex; (2) lesions of occipital cortex; (3) lesions of somatic cortex; and (4) sham ablations. An attempt was made to distribute fast and slow learners equally among these groups.

Surgery was conducted under sodium pentobarbital anesthesia (Diabutal, $50 \mathrm{mg} / \mathrm{kg}$, IP). Bilateral cortical extirpations were accomplished in one operation by aspiration, and lesion sites were based on previously constructed anatomical and evoked potential maps of the cortex (e.g., Welker, 1971, 1972; Zubek, 1951). A midline incision in which the dorsal surface of the skull was exposed constituted the sham ablation. All rats were injected with 100,000 units of benzathine penicillin $G$, and the wound margins were treated with Bacitracin ointment. Ten days of ad-lib feeding constituted the postoperative recovery period. The animals then were placed on the 15-min feeding schedule for 4 days, after which testing recommenced.

\section{Postoperative Testing}

All rats were tested with the same stimuli that they experienced previously, but they were now rewarded on the opposite surface. That is, rats previously rewarded on the grooved surface were now rewarded on the smooth plate, and vice versa. If an animal failed to learn the reversal in 60 days with the same criterion as used preoperatively, it was removed from the study and given a conservative maximum learning score (63 days to criterion) for statistical treatment of its data.

\section{Histology}

The subjects were deeply anesthetized with sodium pentobarbital and perfused with $.9 \%$ saline followed by $10 \%$ Formalin solution injected through the aorta upon completion of testing. Photographs were taken of each brain with lesions, and drawings were made of the cortical surfaces. Coronal sections were cut at $40 \mu$ on a freezing microtome after fixation in a Formalin solution. Every fifth section was saved and stained with cresyl violet for histological verification of the lesions and to assure that there was no direct insult to important underlying structures (e.g., hippocampus).

\section{RESULTS}

A two-way analysis of variance ( 2 learning conditions by 4 surgical groups) was conducted on the number of days required to reach criterion prior to surgery (overall mean $=21.24$ days) after a t test showed that rats rewarded on the milled plate did not differ from those rewarded on the smooth plate. The results of this ANOVA did not reveal any sig- 


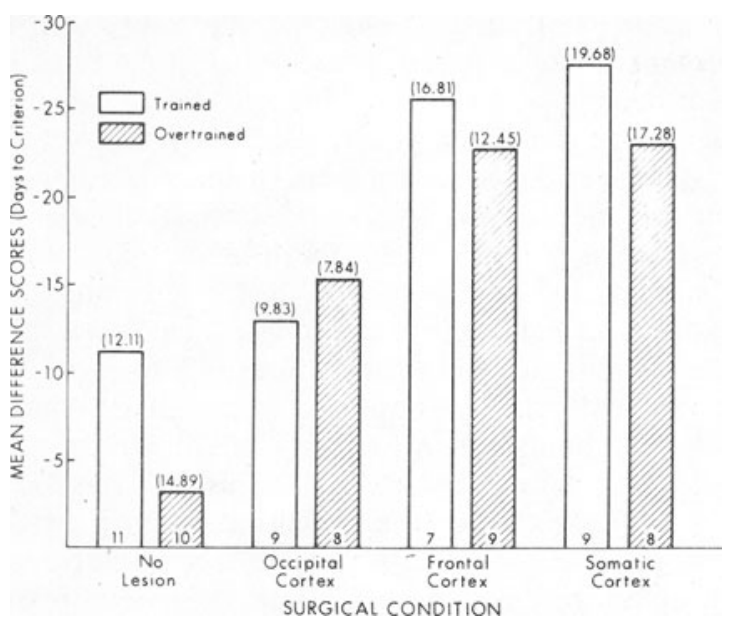

Figure 1. Mean negative difference scores (days to criterion) of eight groups of rats on a tactile reversal problem. Numbers in brackets above bars are standard deviations, and numbers at the base of each bar signify group size.

nificant main or interaction effects in preoperative learning (all ps $>.05$ ). Furthermore, the four groups of rats that received overtraining prior to surgery did not differ from each other in errors during the overtraining period [one-way ANOVA, F $(3,29)=$ $1.55, \mathrm{p}>.05]$. Thus, fast and slow learners appeared to be equally distributed among the groups as they entered surgery. Moreover, the fact that rats exhibited very few or no errors during the overtraining period strongly suggests that learning was well established at the end of the standard testing period.

Figure 1 shows how the eight groups of rats performed after surgery. The difference scores used here were obtained by subtracting postoperative days to criterion from preoperative days to criterion. (Negative difference scores signify that more days were required to meet criterion postoperatively than preoperatively, and large negative difference scores imply that postoperative performance was much poorer than preoperative performance.) A two-way ANOVA on these data revealed a highly significant lesion effect $[\mathrm{F}(3,61)=6.65, \mathrm{p}<.001]$, but no overtraining $[\mathrm{F}(1,61)=.83, \mathrm{p}>.05]$ or lesion-overtraining interaction effects $[\mathrm{F}(3,61)=.39, \mathrm{p}>.05]$.

A Newman-Keuls procedure was used to compare the individual surgical groups to each other after the training variable was collapsed across cells. These comparisons showed that the group with somatic cortex lesions performed significantly worse than the sham-operated and occipital cortex lesion groups (both ps < .05), but not differently from the frontal cortex animals $(p>.05)$. Furthermore, rats with frontal cortex damage were impaired relative to shamoperated animals $(\mathrm{p}<.05)$. All other comparisons were not statistically significant.

Although the mean scores presented in Figure 1 might suggest that the two sham-operated groups are showing a trend toward being different from each other, inspection of the scores of the individual animals revealed that the larger negative difference score of the nonovertrained group was due (a) to 2 of 11 animals that performed exceptionally poorly on the reversal (difference scores of -33 and -24 days to criterion), and (b) to the fact that the rats in this group required the fewest days to meet criterion preoperatively. Nevertheless, because of the significance of this particular comparison, two new groups of sham-operated animals were tested after these data were analyzed. While the replication groups had somewhat better preoperative learning scores than the original groups (they were tested by another experimenter), there still was no evidence for an overtraining reversal effect when their day difference scores were compared with a t test (means of -4.18 and -5.80 with Ns of 11 and 10 for trained and overtrained groups, respectively; $\mathrm{p}>.05$ ).

All postoperative findings with day difference measures were confirmed with additional statistical analyses on the raw scores themselves. In short, no significant differences appeared between rats that were trained and those that were overtrained, while effects due to frontal and somatic cortex surgery again appeared.

Figure 2 presents representative lesions of animals in the somatic, frontal, and occipital cortex lesion groups. The frontal cortex lesions were much smaller than the other ablations, although they resulted in severe deficits, whereas the occipital cortex lesions did not. Although all lesions severely damaged the intended target areas, the somatic cortex lesions were primarily confined to the first somatic sensory area (Welker, 1971) and spared considerable tissue in the second sensory zone (Welker, 1972). Both the frontal and
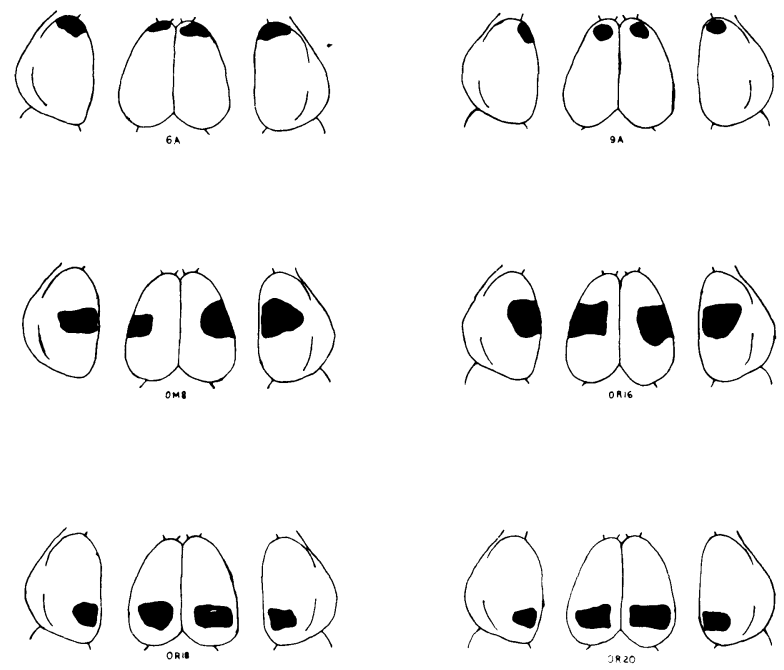

Figure 2. Drawings of representative frontal, somatic, and occipital cortex lesions from trained (left column) and overtrained (right column) groups. 
occipital cortex lesions did not infringe upon the somatic cortex, and, in the case of the frontal animals, the damage appeared to be anterior to the motor areas.

\section{DISCUSSION}

The data collected in the present study show that cortical damage can result in severe deficits on a reversal task. The impairments found with the tactile discriminanda used here, however, were limited to those cases where frontal or somatic cortex was ablated, and not to injuries of the occipital region. Preoperative overtraining was not found to improve reversal performance of the brain-damaged animals, nor was an ORE observed in those rats without cortical lesions.

The lesion data are consonant with earlier reports showing that frontal cortical damage can impair performance on simple (Kolb, Nonneman, \& Singh, 1974) and complex (Bourke, 1954) reversal tasks. The findings in these studies would suggest that the frontal cortex is in some way involved with higher order learning, or with a general factor which is essential for good discriminative performance under difficult conditions (Brush, Mishkin, \& Rosvold, 1964). The deficits displayed by these animals may, for example, be due to increased distractability, difficulties in attention span, or problems in overcoming spontaneous preferences (Brush et al., 1961; Maher, 1955; Malmo, 1942; Mishkin, Rosvold, \& Pribram, 1953). The large number of perseverative errors and position habits displayed by the animals in this group would be consistent with such an interpretation. Insofar as not all investigators have observed comparable effects of frontal lobe lesions on reversal tasks (see Hannon \& Bader, 1974; Jeeves, 1967), one should consider the possibility that these effects can be greatly influenced by lesion size and locus, particular task demands, and training variables, factors known to be extremely important in lesion studies in general (Finger, 1978).

The data also confirm the role of the somatic cortex on problems involving tactile stimuli (Finger, 1974). The deficits exhibited by these rats probably reflect factors which are different from those which led to quantitatively similar impairments in animals with frontal cortex lesions. For example, both sensory losses and motor impairments may result from large lesions of the two somatosensory areas of the cortex (Finger, Simons, \& Posner, 1978; Glassman, 1970; Norrsell, 1971, 1978). With the tactile stimuli used here, the latter may be just as important as the former in that good performance would depend upon the ability of the subject to position its paws in a way which would maximize appreciation of the tactile stimuli. With regard to reversal tasks, it is possible that even small deficits which might normally be overcome with cue and strategy selection changes could become increasingly difficult to cope with under more demanding test conditions. Some support for this contention comes from related work from this laboratory; this work shows that sensorimotor cortical lesions can result in deficits which are potentiated under certain test conditions that do not involve changes in the physical characteristics of the stimuli (see Finger \& Simons, 1976). The fact that rats with these lesions can learn difficult nontactile discriminations as rapidly as control animals should be stressed (Finger, 1974). This task specificity strongly suggests that the deficits displayed on the tactile problems do not simply reflect impairments in motivation, emotion, attention, or general learning abilities, factors which are more likely to be associated with frontal cortex damage.

Damage to the occipital cortex had little effect on tactile reversal learning. This may be viewed as contrasting with earlier reports which have shown that these ablations can impair visual reversals (LeVere \& Morlock, 1973) and, under some conditions, spatial reversal learning (Thorne \& Thompson, 1970). The new data imply that the effects of posterior cortical lesions on reversal learning may be somewhat more specific to problem type than has previously been recognized. It is important to remember that these lesions were considerably larger than the frontal cortical lesions which were greatly incapacitating to the rats. This finding opposes the position that a lesion of any cortical area can affect reversal learning, and it argues against the contention that reversal deficits are simply a function of lesion size.

The hypothesis that overtraining can lessen the deficits displayed by animals with cortical ablations was not supported by the findings obtained in the current investigation. This is interesting because overtraining has been found to attenuate tactile performance deficits after somatosensory cortical lesions on tasks not involving reversal learning (Weese et al., 1973). In addition, overtraining may also lessen the deficits that follow other cortical (Chow \& Survis, 1958; Orbach \& Fantz, 1958) and subcortical (Lukaszewska \& Thompson, 1967) lesions when retention is assessed. The results reported here may mean that the recovery effects seen in earlier experiments with overtraining and brain lesions may, in fact, not generalize across a wide range of events and circumstances. This important issue has been discussed by Geschwind (1974) in the context of language disorders after left hemispheric damage in humans. After mentioning that overlearning has been shown to enhance recovery of some functions in animals, Geschwind (p. 490) nevertheless points out that patients may show severe and prolonged deficits in the ability to use language after lesions of the speech areas although 
this "may be the most overlearned skill they possess."

The failure of the ORE to appear among the shamoperated animals was also surprising. While this may seem to contradict many of the experiments which have been conducted on the ORE (cf. Lovejoy, 1966; Mackintosh, 1969), it remains plausible that the choice of stimuli (e.g., tactile vs. visual) is a critical variable in these investigations. The ORE has not been assessed with tactile stimuli in the past, and it may be that the visual and spatial stimuli typically employed in these studies have certain features which permit the ORE to be demonstrated more easily (see, for example, Richman, Knoblock, \& Coussens, 1972). Further investigations with other types of problems may aid in determining the conditions under which the ORE can be observed, and the inclusion of lesion material in such experiments may enhance our understanding of the basis and significance of these phenomena.

\section{REFERENCES}

Bignami, G., Carro-Ciampi, G. \& Albert, M. Effects of frontal lesions on "go-no go" avoidance behavior in normal and scopolamine-treated rats. Physiology \& Behavior, 1968, 3, 487-494.

Bourke, W. T. The effects of frontal lobe damage upon habit reversal in the white rat. Journal of Comparative and Physiological Psychology, 1954, 47, 277-282.

Brush, E. S., Mishin, M., \& Rosvold, H. E. Effects of object preferences and aversions on discrimination learning in monkeys with frontal lesions. Journal of Comparative and Physiological Psychology, 1961, 54, 319-325.

Chow, K. L., \& Survis, J. Retention of overlearned visual habit after temporal ablation in the monkey. Archives of Neurology and Psychiatry, 1958, 79, 640-646.

DENNY, M. R. Elicitation theory, applied to an analysis of the overlearning reversal effect. In J. H. Reynierse (Ed.), Current issues in animal learning. New York: Academic Press, 1970.

FINGER, S. Recovery after somatosensory forebrain damage. In G. Stein, J. J. Rosen, \& N. Butters (Eds.), Plasticity and recovery of function in the central nervous system. New York: Academic Press, 1974.

FINGER, S. (ED.) Recovery from brain damage: Research and theory. New York: Plenum, 1978.

Finger, S., Cohen, M., \& Alongi, R. Roles of somatosensory cortical areas 1 and 2 in tactile discrimination in the rat. International Journal of Psychobiology, 1972, 2, 93-102.

Finger, S., \& Frommer, G. P. Effects of cortical lesions on tactile discriminations graded in difficulty. Life Sciences, 1968, 7, 897-904.

Finger, S., \& Simons, D. Effects of serial lesions of somatosensory cortex and further neodecortication on retention of a rough-smooth discrimination in rats. Experimental Brain Research, 1976, 25, 183-197.

Finger, S., Simons, D., \& Posner, R. Anatomical, physiological, and behavioral effects of neonatal sensorimotor cortex ablation in the rat. Experimental Neurology, 1978, 60, 347-373.

Fonberg, E., Brutkowski, S., \& Mempel, E. Defensive conditioned reflexes and neurotic motor reactions following amygdalectomy in dogs. Acta Biologiae Experimentalis (Warsaw), 1962, 22, 51-57.

Gabriel, M., Saltwick, S. E., \& Kampschaefer, G. An overtraining reversal effect with differential avoidance conditioning in rabbits. Bulletin of the Psychonomic Society, 1977, 10, 81-82.
Geschwind, N. Late changes in the nervous system: An overview. In D. G. Stein, J.J. Rosen, \& N. Butters (Eds.), Plasticity and recovery of function in the central nervous system. New York: Academic Press, 1974.

Glassman, R. B. Cutaneous discrimination and motor control following somatosensory cortical ablations. Physiology \& Behavior, 1970, 5, 1009-1019.

Glendenning, R. L. Effects of training between two unilateral lesions of visual cortex upon ultimate retention of black-white discrimination habits by rats. Journal of Comparative and Physiological Psychology, 1972, 80, 216-229.

Hall, G. Transfer effects produced by overtraining in the rat. Journal of Comparative and Physiological Psychology, 1974, 87, 938-944.

Hannon, R., \& Bader, A. A comparison of frontal pole, anterior median and caudate nucleus lesions in the rat. Physiology \& Behavior, 1974, 13, 513-521.

JEEVES, M. A. Some paradoxical effects of bilateral lesions in the frontal cortex in rats. Neuropsychologia, 1967, 5, 73-84.

Kolb, B., Nonneman, A. J., \& Singh, R. K. Double dissociation of spatial impairments and perseveration following selective prefrontal lesions in rats. Journal of Comparative and Physiological Psychology, 1974, 87, 772-780.

LASHLEY, K. S. Studies of cerebral functioning of long continued practice upon cerebral localization. Journal of Comparative Psychology, 1921, 1, 453-468.

LEVERE, T. E., \& MorLOCK, G. W. Nature of visual recovery following posterior neodecortication in the hooded rat. Journal of Comparative and Physiological Psychology, 1973, 83, 62-67.

Lovejoy, E. Analysis of the overlearning reversal effect. Psychological Review, 1966, 73, 87-103.

Lukaszweska, I., \& Thompson, R. Retention of overtrained pattern discrimination following pretectal lesions in rats. Psychonomic Science, 1967, 8, 121-122.

Mackintosh, N. J. The psychology of animal learning. London: Academic Press, 1974.

Maher, B. A. Anticipatory and perseverative errors following frontal lesions in the rat. Journal of Comparative and Physiological Psychology, 1955, 48, 102-105.

MaLmo, R. B. Interference factors in delayed response in monkeys after removal of frontal lobes. Journal of Neurophysiology, 1942, 5, 295-308.

Mishin, M., Rosvold, H. E., \& Pribram, K.H. Effects of Nembutal in baboons with frontal lesions. Journal of Neurophysiology, 1953, 16, 155-159.

NorSELL, U. A comparison of functions of the first and second somatosensory areas of the dog. Experientia, 1971, 27, 1284.

Norrsell, U. Sensory deficits caused by lesions of the first (SI and second (SII) somatosensory areas of the dog. Experimental Brain Research, 1978, 32, 181-195.

OrbaCh, J., \& FanTz, R. L. Differential effects of temporal neocortical resections on overtrained and non-overtrained visual habits in monkeys. Journal of Comparative and Physiological Psychology, 1958, 51, 126-129.

PAuL, C. Effects of overlearning upon single habit reversal in rats. Psychological Bulletin, 1965, 63, 65-72.

REID, L. S. The development of noncontinuity behavior through continuity learning. Journal of Experimental Psychology, 1953, 46, 107-112.

Richman, C. L., Knoblock, K., \& Coussens, W. The overtraining reversal effect in rats: A function of task difficulty. Quarterly Journal of Experimental Psychology, 1972, 24, 291-298.

Sperling, S. E. Reversal learning and resistance to extinction: A review of the rat literature. Psychological Bulletin, 1965, 63, 281-297.

Sutherland, N. S., \& Mackintosh, N. J. Mechanisms of animal discrimination learning. New York: Academic Press,
1971. 
Thatcher, P. W., \& Kimble, D. P. Effect of amygdaloid lesions on retention of an avoidance response in overtrained and non-overtrained rats. Psychonomic Science, 1966, 6, 9-10.

Thorne, M. B., \& Thompson, R. Position reversal as affected by occipital, posterior thalamic, and rubral lesions in the white rat. Psychonomic Science, 1970, 18, 189-190.

Weese, G. D., Neimand, D., \& Finger, S. Cortical lesions and somesthesis in rats: Effects of training and overtraining prior to surgery. Experimental Brain Research, 1973, 16, 542-550.

WeLKER, C. Microelectrode delineation of fine-grain somatotopic organization of SmI cerebral neocortex in albino rat. Brain Research, 1971, 26, 259-275.

WELKER, C. Somatotopic organization of SmII cerebral neocortex in albino rat. Brain Research, 1972, 37, 132-136.

ZuвEK, J. P. Recent electrophysiological studies of the cerebral cortex: Implications for localization of sensory functions. Canadian Journal of Psychology, 1951, 5, 110-121.

(Received for publication March 31, 1979; revision accepted July 13, 1979.) 